\title{
Analisis biomekanika free throw basket sesuai kaidah dave hopla
}

\author{
Fajar Awang Irawan*, Wisnu Kerja Raharja, Tafriyadhur Risa Billah, Mirza Arif Ma'dum \\ Jurusan Ilmu Keolahragaan, Fakultas Ilmu Keolahragaan, Universitas Negeri Semarang, \\ Sekaran, Kecamatan Gunungpati, Kota Semarang, Jawa Tengah 50229, Indonesia \\ * Coressponding Author. E-mail: fajarawang@ mail.unnes.ac.id
}

Received: April 25, 2021; Accepted: August 20, 2021; Published: September 25, 2021

\begin{abstract}
Abstrak: Penelitian ini bertujuan untuk menganalisis gerakan free throw sesuai dengan kaidah Dave Hopla. Metode penelitian ini menggunakan deskriptif kuantitatif dengan survey tes dan pengukuran. Total sampel berjumlah 5 atlet PPLP Basket Kota Semarang yang telah mengisi inform consent dan menyetujui prosedur penelitian. Hasil penelitian ini didapatkan rata rata waktu pada tahap persiapan sebesar $0,53 \pm$ 0,13 detik dengan sudut ayunan sebesar $120^{\circ}$. Gerakan awalan sudut lengan $90^{\circ}$ dan rata rata waktu $0,25 \pm$ 0,04 detik dengan sudut fleksi lutut sebesar 99,04 $\pm 0,04$ derajat. Data pada tahap pelaksanaan untuk waktu yang diperoleh sebesar 0,29 $\pm 0,07$ detik dengan sudut fleksi lengan sebesar 55,74 $\pm 5,54$ derajat sedangkan pada tahap akhir dengan rata rata waktu 0,24 $\pm 0,04$ detik dengan jarak shooting 3,64 \pm 4,64 meter. Kesimpulan dalam penelitian ini menunjukkan bahwa gerakan free throw sudah sesuai dengan kaidah dari Dave Hopla. Hasil free throw juga menunjukkan bahwa shooting precision pada kategori Cukup. Keterbatasan dalam penelitian ini yaitu jumlah sampel yang sedikit terkendala pembatasan social pada masa pandemic Covid-19. Penelitian selanjutnya diharapkan bahwa kaidah Dave Hopla dapat dijadikan sebagai rujukan dalam melakukan free throw untuk efektivitas dan efisiensi gerakan serta akurasi shooting.

Kata Kunci: analisis gerak, free throw, basket, dave hopla
\end{abstract}

\section{Biomechanical analysis of basketball free throw according to the rules of dave hopla}

\begin{abstract}
This aims of this study was to analyze the free throw motion according to Dave Hopla's rules. This research method uses descriptive quantitative with survey tests and measurements. The total sample consisted of 5 PPLP Basket athletes in Semarang who had filled the informed consent and approved the research procedure. The results of this study found an average time in the preparation phase was $0.53 \pm$ 0.13 seconds with a swing angle of $120^{\circ}$. The prefix movement of the arm angle was $90^{\circ}$ and an average time was $0.25 \pm 0.04$ seconds with a knee flexion angle of $99.04 \pm 0.04$ degrees. The data at the implementation phase for the time obtained were $0.29 \pm 0.07$ seconds with an arm flexion angle was 55.74 \pm 5.54 degrees while in the follow through phase an average time was $0.24 \pm 0.04$ seconds with a shooting distance of $3.64 \pm 4.64$ meters. The conclusion of this study showed that the free throw motion is in accordance with Dave Hopla's rules. The free throw result also showed that the shooting precision is in the Moderate category. The limitation in this study was the sample size is slightly constrained by social restrictions during the Covid-19 pandemic. Further research is expected that Dave Hopla's rule can be a reference in making effective and efficient free throws.
\end{abstract}

Keywords: motion analysis, free throw, basketball, dave hopla

How to Cite: Irawan, F. A., Raharja, W. K., Billah, T. R., \& Ma'dum, M. A. (2021). Analisis biomekanika free throw basket sesuai kaidah dave hopla, Jurnal keolahragaan, 9(2), 210-219. doi: https://doi.org/10.21831/jk.v9i2.40360

\section{PENDAHULUAN}

Permainan bola basket merupakan permainan beregu. Dalam permainan bola basket yang baku, setiap tim memiliki lima pemain di lapangan (Rudiansyah et al., 2014). Tujuan dari permainan bola basket adalah memasukkan bola ke dalam ring. Sehingga teknik dasar yang utama dan harus dikuasai adalah menembak bola (shooting). Menurut Asmawan \& Wismanadi, (2019) shooting merupakan kemampuan untuk menembak bola dengan memasukkan bola ke ring lawan untuk mencetak poin. 
Shooting merupakan salah satu hal terpenting dari beberapa teknik dasar bermain bola basket yang harus dikuasai sebagai seorang pemain. Dalam permainan bola basket tembakan merupakan kunci utama dari terciptanya sebuah angka. Sikap postur dan posisi badan harus diperhatikan ketika akan menembak. Posisi badan juga harus memenuhi prinsip dasar gerakan dalam melakukan shooting. Mulai dari posisi tangan, tungkai, pandangan, keseimbangan dan irama tembakan (Rudiansyah et al., 2014).

Kemenangan dari sebuah tim tidak selalu diukur dari aksi yang besar tetapi dari hal kecil sekalipun kemenangan tersebut dapat diwujudkan. Ketatnya pertandingan membuat hal - hal yang kecil dapat menjadi penentu permainan dapat dimenangkan oleh sebuah tim. Tidak terkecuali tembakan yang hanya menghasilkan 1 poin sekalipun. Free throw merupakan suatu tembakan yang diperoleh dari pelanggaran dan kesalahan, baik dari kesalahan tim sendiri maupun didapat dari pelanggaran lawan. Free throw merupakan kesempatan yang diberikan kepada seorang pemain untuk mencetak 1 (satu) angka, tidak dijaga, dari posisi dibelakang garis free throw dan di dalam setengah lingkaran (Sartika, 2010). Free throw yang secara umum sering disebut tembakan bebas adalah tembakan yang dihadiahkan kepada seorang pemain untuk mendapatkan angka, sebagai akibat diganggunya dengan kasar oleh pemain lawan dalam usaha tembakan lapangan (Hung et al., 2004). Kenyataanya dari banyaknya latihan yang diberikan kepada pemain, free throw seakan - akan hanya menjadi latihan yang dianggap tidak terlalu penting dan dapat dipelajari sendiri oleh pemain. Padahal keuntungan yang di dapat dari free throw sangat besar yaitu dapat menyelamatkan sebuah tim dari kekalahan. Karena pada dasarnya seorang pemain yang mendapatkan free throw tidak akan mendapat penjagaan dari lawan. Meskipun free throw dapat dikatakan mudah dari segi teknik tembakan bila dibandingkan dengan shooting yang lainnya, tetapi pada kenyataannya tidak semua pemain mahir dalam melakukan tembakan ini. Free throw membutuhkan konsentrasi dan teknik dasar tembakan yang benar. Atlet PPLP Basket Kota Semarang saat bertanding mendapatkan masukan yang dapat diketahui melalui evaluasi pelatih dan tim manajer dimana stance kaki terlalu melebar, togok terlalu tegak, sudut siku yang melebar, dan tidak ada koordinasi antara tangan dan bahu saat melakukan shooting.

Menurut Rubiana (2017) gerakan free throw bukan hanya sekedar asal melemparkan bola saja, tetapi juga meliputi gerakan mengarahkan dan mengusahakan bola supaya jatuh tepat di sasaran. Jadi supaya dapat melihat bagaimana gerakan yang dilakukan benar dibutuhkan analisis gerak yang dapat dilihat berulang ulang dan dapat ditambahkan keterangan data dalam video. Gerakan yang diamati tersebut nantinya lebih mudah untuk dianalisa melalui mekanisme gerakan yang terkait dengan sudut serta efisiensi gerakan terhadap tembakan bola ke dalam ring. Irawan \& Long-Ren, (2015); Irawan, Permana, Akromawati, \& Yang-tian, (2019) menyampaikan bahwa biomekanika olahraga mempunyai beberapa tujuan, di antaranya mengetahui gerakan yang efektif dan efisien dalam suatu rangkaian gerak dan mengetahui faktor apa yang mempengaruhi keberhasilan. Sebab itu perlu diketahui teknik yang paling tepat untuk dapat menganalisa mekanisme sudut serta efisiensi gerakan. Irawan \& LongRen (2019) menjelaskan bahwa analisis biomekanik dapat membantu tentang pengetahuan teknik yang benar dan dapat memberikan evaluasi peforma atau penampilan, pengawasan secara bertahap dan adanya catatan koreksi gerakan yang kurang efektif dan berfungsi sebagai referensi serta berguna untuk pengembangan dan peningkatan kinerja gerak. Teknik gerakan yang benar melalui aspek mekanika akan meminimalisir terjadinya kesalahan dan untuk mengoreksi gerakan yang di anggap tidak sesuai dalam melakukan shooting bola ke dalam ring tersebut sehingga atlet secara berkala akan memperbaiki gerakannya menjadi lebih sempurna dengan prinsip mekanika.

Menurut penelitian Asmawan \& Wismanadi, (2019) menyebutkan bahwa kegagalan dalam melakukan free throw juga dapat diakibatkan oleh fundamental teknik free throw yang salah. Oleh karena itu perlu adanya analisis kaidah dasar free throw sebagai acuan untuk dapat menyamakan mekanika gerak yang diperagakan oleh atlet sendiri dalam meraih kemenangan pada suatu pertandingan. Penerapan mekanika yang sudah dibahas Hopla, (2013) tentang bagaimana cara melakukan teknik tembakan. Mulai dari free shots dan midrange jump shoots yang dikemas melalui pembelajaran yang mudah dipahami. Informasi dilengkapi dengan analisis gerak, panduan gerakan, dan penjelasan yang runtut dari mulai memegang bola sampai melepaskan bola ke dalam ring. Rujukan tersebut dapat dijadikan sebagai pedoman dalam analisis gerak dan evaluasi terhadap perbaikan gerakan dalam free throw pada basket. Permasalahan yang ditemui dilapangan yaitu atlet Pusat Pembinaan dan Latihan Olahraga Pelajar (PPLP) di Kota Semarang saat melakukan free throw 
kurang efektif dengan rata rata atlet memiliki prosentase $60 \%$ tembakan yang masuk di ring. Hal ini berimbas pada saat pertandingan uji coba dengan salatiga dimana prosentase free throw yang masuk hanya $30 \%$. Berdasarkan pengamatan pelatih didapatkan beberapa kendala seperti jumlah tembakan yang kurang saat latihan, focus saat melakukan free throw, dan kesesuaian gerakan saat melakukan free throw masih menjadi kendala. Oleh karena itu peneliti merasa tertarik untuk melakukan analisis biomekanika dalam mengetahui kelemahan saat melakukan free throw pada atlet. Tujuan penelitian ini untuk menganalisa gerakan free throw sesuai dengan kaidah Dave Hopla. Hasil dari analisis ini harapanya dapat menjadi rujukan dalam perbaikan kinerja dan peningkatan performa dalam melakukan free throw.

\section{METODE}

Jenis penelitian yang digunakan dalam penelitian ini merupakan penelitian deskriptif kuantitatif. Data kuantitatif diperoleh dari data kinematic dari analisis gerak menggunakan video recording sesuai dengan (Aksović et al., 2015). Analisis biomekanika gerakan free throw dianalisis menggunakan aplikasi software Dartfish (version 8, GEAR Software B.V., Helmond). Penelitian ini menggunakan pendekatan survei, dengan teknik survei tes yaitu dengan tes dan pengukuran free throw dan precesion test yang digunakan untuk mengukur gejala-gejala dan kejadian (Abdullah, 2015) melalui analisis gerak menggunakan video recording yang mempengaruhi free throw pada basket.

Terkait dengan kondisi pandemic Covid-19 dan diterapkannya pembatasan sosial berskala besar (PSBB) untuk memutus rantai penularan Covid-19 maka terdapat beberapa kendala dalam penarikan sampel penelitian seperti tidak semua atlet berkenan hadir dalam penelitian dan terdapatnya kekhawatiran atlet terhadap penularan Covid 19 ditempat penelitian. Sehingga teknik purposive sampling sangat efektif untuk merekrut sampel yang pada kondisi saat ini tidak memungkinkan untuk seluruh atlet hadir dan mengikuti penelitian karena memang harus sesuai dengan protocol kesehatan dan sampel bersedia untuk menjadi partisipan dalam penelitian. 5 dari 12 atlet PPLP Basket Kota Semarang yang hadir telah menyetujui dan menandatangani lembar inform consent dan telah dinyatakan negative pada swab tes antigen. Ketaatan protocol kesehatan juga diterapkan dalam penelitian dimana disediakan tempat cuci tangan dan sabun, penggunaan masker dan tetap menjaga jarak antara satu orang sengan orang lain. Penelitian ini telah disetujui oleh Komisi Etik Penelitian Universitas Negeri Semarang, Indonesia dengan nomor 082/KEPK/EC/2020 berdasarkan Standards and Operational Guidance for Human Participants pada WHO tahun 2011.

Penelitian ini menggunakan teknik analisis data dengan bantuan software Dartfish versi 8 dimana setiap rangkaian fase gerak diidentifikasi frame by frame dan cek data kinematiknya yang meliputi waktu free throw, sudut lemparan, jarak shooting, dan tinggi bola. Software Dartfish versi 8 ini memberikan rangkaian lengkap pada peralatan analisis video yang meliputi analyzer dan slow motion yang menjadikan video dapat diputar secara lambat sehingga tahapan-tahapan gerakan free throw dapat dilihat dengan jelas dan rinci (Kartiko et al., 2019). Prosedur penelitian meliputi perekaman video gerakan free throw yang kemudian di input ke dalam analyzer untuk mengetahui dan memberikan sudut-sudut serta kemungkinan-kemungkinan kesalahan gerak yang dilakukan oleh sampel penelitian. Data berupa video dan gambar yang didapat kemudian dianalisis, sehingga dapat diketahui kekurangan atau kelemahan atlet ketika melakukan rangkaian gerakan free throw. Analisis gerakan difokuskan pada fase persiapan, awalan, pelaksanaan dan fase akhir yang meliputi sudut tungkai, sudut lengan, sudut tembakan, sudut curve dan sudut tolakan pada angkle saat berjinjit.

\section{HASIL DAN PEMBAHASAN}

Hasil penelitian ini ditampilkan dalam bentuk tabel dan diagram untuk mengetahui jumlah distribusi frekuensi dari awal hingga akhir tes yang didapat dari penelitian ini.

Tabel 1. Distribusi data atlet

\begin{tabular}{cccc}
\hline $\mathbf{n}=\mathbf{5}$ & Mean $\pm \mathbf{S D}$ & Min & Max \\
\hline TB $(\mathrm{cm})$ & $168,2 \pm 4,66$ & 163 & 175 \\
BB $(\mathrm{Kg})$ & $56,5 \pm 5,07$ & 61 & 51 \\
Usia (Thn) & $16,4 \pm 0,55$ & 16 & 17 \\
\hline
\end{tabular}


Hasil distribusi data atlet pada tabel 1 menunjukan bahwa rata-rata tinggi badan sampel sebesar $168,2 \pm 4,66 \mathrm{~cm}$, dan berat badan 56,5 $\pm 5,07 \mathrm{~kg}$. Berat badan atlet tertinggi sebesar $61 \mathrm{~kg}$ dan terendah sebesar $51 \mathrm{~kg}$. Sedangkan rata-rata usia sampel 16,4 tahun dengan usia tertinggi sebesar 17 tahun dan terendah sebesar 16 tahun. Hasil analisis video dalam penelitian ini menggunakan software aplikasi Dartfish versi 8 yang tersaji pada tabel 2 sebagai berikut:

Tabel 2. Data analisis atlet

\begin{tabular}{|c|c|c|c|}
\hline $\mathrm{n}=5$ & Value & Min & $\operatorname{Max}$ \\
\hline & \multicolumn{3}{|c|}{ Tahap persiapan } \\
\hline Waktu free throw/ W (s) & $0,553 \pm 0,13$ & 0,43 & 0,9 \\
\hline Sudut lengan / SL (०) & $84,14 \pm 9,88$ & 70,5 & 94 \\
\hline Jarak shooting/ J (m) & $4,13 \pm 0,06$ & 4,06 & 4,2 \\
\hline \multirow[t]{2}{*}{ Tinggi bola/ T (m) } & $1,68 \pm 0,04$ & 1,63 & 1,75 \\
\hline & \multicolumn{3}{|c|}{ Tahap awalan } \\
\hline Waktu free throw/ W (s) & $0,25 \pm 0,04$ & 0,2 & 0,299 \\
\hline Sudut tungkai / ST ( $\left.{ }^{\circ}\right)$ & $99,04 \pm 0,04$ & 9,25 & 113,5 \\
\hline Jarak shooting/ J (m) & $4,13 \pm 0,06$ & 4,06 & 4,2 \\
\hline \multirow[t]{2}{*}{ Tinggi bola / T (m) } & $1,83 \pm 0,06$ & 1,7 & 1,9 \\
\hline & \multicolumn{3}{|c|}{ Tahap pelaksanaan } \\
\hline Waktu free throw/ W (s) & $0,29 \pm 0,07$ & 0,2 & 0,4 \\
\hline Sudut lengan / SL (०) & $55,74 \pm 5,54$ & 46,4 & 60 \\
\hline Jarak shooting/ J (m) & $4,13 \pm 0,06$ & 4,06 & 4,2 \\
\hline \multirow[t]{2}{*}{ Tinggi bola/ T (m) } & $2,15 \pm 0,19$ & 1,94 & 2,35 \\
\hline & \multicolumn{3}{|c|}{ Tahap akhir } \\
\hline Waktu free throw/ W (s) & $0,24 \pm 0,04$ & 0,2 & 0,266 \\
\hline Jarak shooting/ J (m) & $3,64 \pm 3,64$ & 0,12 & 3,5 \\
\hline Tinggi bola/ T (m) & $3,62 \pm 3,62$ & 0,12 & 3,5 \\
\hline
\end{tabular}

Hasil penelitian pada tabel 2 dapat diketahui melalui tahapan persiapan dengan rata-rata waktu yang diperoleh $0,533 \pm 0,13$ detik, dengan nilai minimal 0,43 detik dan nilai maksimal 0,9 detik. Sedangkan pada tahap awalan waktu free throw $0,25 \pm 0.04$ detik, dengan waktu minimal 0,2 detik dan waktu maksimal 0.299. Untuk waktu yang dibutuhkan pada tahap pelaksanaan didapatkan $0,29 \pm$ 0.07 detik dengan waktu minimal 0,2 detik dan waktu maksimal 0.4 detik. Gerakan free throw pada tahap akhir memperlihatkan waktu yang diperoleh sebesar $0,24 \pm 0,04$ detik dengan waktu minimal 0,2 detik dan waktu maksimal 0,266 detik. Rata rata sudut ekstensi pada lengan di tahap persiapan sebesar 84,14 \pm 9.88 derajat. Sedangkan pada tahap awalan sebesar 99,04 $\pm 0,04$ derajat dan pada tahapan pelaksanaan didapatkan 55,74 $\pm 5,54$ derajat. Rata rata tinggi bola free throw pada tahap pelaksanaan sebesar 2,15 $\pm 0,19$ meter sebelum bola menggapai ring. Sedangkan pada tahap akhir bola lambung hasil free throw didapatkan tinggi sebesar 3,62 \pm 3,62 meter. Parameter data kinematic ini merujuk pada instrument yang digunakan oleh Ammar, Chtourou, Abdelkarim, Parish, \& Hoekelmann, (2016) serta Boddington, (2019) yang membahas tentang parameter kinematic pada free throw terhadap performa penampilan basket selama proses pembelajaran dan identifikasinya terhadap faktor yang berpengaruh pada kesuksesan free throw.

Dalam penelitian ini terdapat empat tahapan dalam melakukan gerakan free throw. Tahapan tersebut terdiri dari tahap persiapan, tahap awalan, tahap pelaksanaan, dan tahap akhir. Pada tahap persiapan didapatkan rata-rata data waktu untuk melakukan free throw $0,53 \pm 0,13$ detik dan tinggi bola pada tahapan tersebut 1,68 $\pm 0,04$ meter. Tahapan persiapan ini mengoptimalkan posisi kuda kuda pelempar dengan salah satu kaki berada di depan dan dibuka selebar bahu. Posisi kuda-kuda ini merupakan teknik dasar dari free throw yang harus dikuasai sejak awal. Posisi kaki, lutut, pinggul, siku, bahu, pergelangan tangan, dan bola harus selalu sejajar dengan kaki tumpuan. Kaidah free throw menurut Dave Hopla pada tahap persiapan disampaikan bahwa hal yang dilakukan adalah membuka kaki selebar bahu dan ditekuk membentuk sudut 120 derajat, kaki sejajar dengan arah ring, sedangkan lutut dan pinggul membungkuk, lutut merendah dan tumit sedikit terangkat dari lantai.

Gerakan pada tahap awalan diketahui data pada rata-rata waktu free throw $0,25 \pm 0,04$ detik dengan sudut fleksi lutut sebesar 99,04 $\pm 0,04$ derajat. Gerakan ini didukung dengan segmen lengan seperti membentuk huruf L dimana sendi siku melakukan ekstensi untuk mendorong bola pada 
tahapan gerakan selanjutnya. Berdasarkan rujukan dari Yulianto, (2018) di sampaikan bahwa tahap awalan yang dilakukan adalah mengangkat siku dengan membentuk seperti huruf $\mathrm{L}$ dan membentuk sudut 90 derajat yang dalam hal ini sudah sesuai dengan praktek dilapangan pada penelitian ini dimana data dilapangan diperoleh dari segmen lutut sebesar 99,04 yang secara signifikan sudah sesuai.

Tahap selanjutnya ada pada tahap pelaksanaan dimana rata-rata waktu yang diperlukan sebesar $0,29 \pm 0,07$ detik dengan sudut fleksi lengan sebesar 55,74 \pm 5,54 derajat dengan maksud memberikan gerakan pantulan seperti memompa sendi siku yang akan melepaskan bola kearah ring basket. Pandangan mata tetap focus pada ring dengan focus gerakan pada lengan dan tungkai saat melakukan ekstensi. Gerakan yang sama dengan pedoman pada Dave Hopla disebutkan bahwa tahapan ini memiliki focus pada teknik pegangan bola dan posisi tangan terhadap bola yang rileks tetapi tetap focus pada pegangan. Pada tahap pelaksanaan ini dibutuhkan koordinasi antar bagian tubuh dan segmen supaya terjadi kesesuaian antara gerak dalam melakukan suatu rangkaian gerak. Hal ini memungkinkan terjadinya pembahasan yang lebih prioritas dan focus pada gerakan untuk tujuan peningkatan performa dan pencegahan cidera (Irawan \& Long-ren, 2019; Irawan \& Long-Ren, 2015a). Sehingga nantinya hasil data yang didapatkan bisa menjadi dasar dalam penelitian yang akan dilakukan selanjutnya.

Analisis gerak pada tahap akhir yaitu pada ekstensi lengan dimana gerakan tersebut di dukung oleh togok dan tungkai pada saat memompa dan melepas bola. Pada tahap akhir ini rujukan dari Dave Hopla terkait analisis Biomekanika yang disampaikan adalah bahwa posisi siku ditempatkan didekat pelipis ketika gerakan follow through berlangsung. Tangan kiri sebagai penyeimbang dalam memegang bola tetap lurus dan focus pada gerakan yang menjadi rangkaian dalam melakukan gerakan free throw. Lengan dan bahu serta tubuh menjadi penopang dalam membentuk sudut 151 derajat dengan lengan dan tangan berada diposisi di atas udara sebelum sampai pada ring. Yang menjadi catatan penting adalah bahwa atlet jangan beranjak dari posisi ketika bola belum sampai keranjang. Hal ini dimaksudkan supaya keseimbangan dan stabilitas tubuh setelah melakukan free throw supaya tetap terjaga.

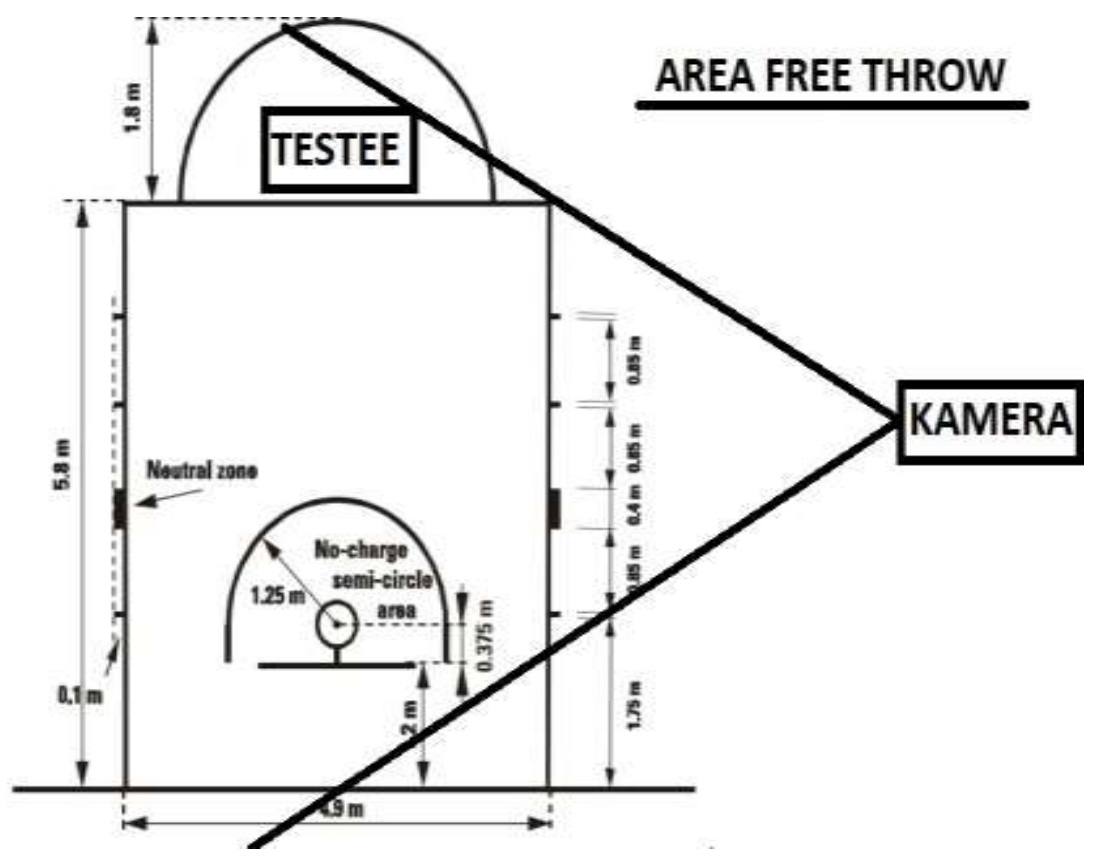

Gambar 1. Area Free Throw (Asmawan \& Wismanadi, 2019)

Prosedur penelitian yang dilakukan merujuk pada Asmawan \& Wismanadi, (2019) dengan area kamera berada disamping lapangan posisi secara sagital dan dapat mencover wilayah antara ring basket yang menjadi target lemparan dengan daerah free throw (gambar 1). Free throw yang dilakukan tidak hanya mendapatkan data kinematic gerakan yang dilakukan, akan tetapi hasil free throw juga diperoleh dengan menggunakan shooting precision (Erčulj \& Štrumbelj, 2015). 
Jurnal Keolahragaan 9 (2), 2021 - 215

Fajar Awang Irawan, Wisnu Kerta Raharja, Tafriyadhur Risa Billah, Mirza Arif Ma'dum

Hasil shooting precision pada free throw menunjukkan bahwa rata rata sampel pada kategori Cukup (68\%). Penjelasan terkait hasil data ini ditampilkan pada tabel 3.

Tabel 3. Distribusi skor hasil shooting precision

\begin{tabular}{ccc}
\hline n= 5 & Presentase & Kategori \\
\hline Sampel 1 & $73,32 \%$ & Baik \\
Sampel 2 & $62,5 \%$ & Cukup \\
Sampel 3 & $77,5 \%$ & Baik \\
Sampel 4 & $65,83 \%$ & Cukup \\
Sampel 5 & $60,83 \%$ & Cukup \\
\hline Rata - rata & $68,00 \%$ & Cukup \\
\hline
\end{tabular}

Tabel 3 di atas menunjukan bahwa prosentase rata rata dari hasil free throw adalah 68,00\% dengan persentase tertinggi sebesar $77,5 \%$ dengan kriteria Baik dan persentase terendah sebesar 60,83\% dengan kriteria Cukup. Rata rata dari hasil penelitian ini merepresentasi bahwa hasil free throw yang dilakukan dalam kategori Cukup dimana kemungkinan hasil tembakan melalui free throw lebih dari 50\% masuk kedalam ring. Hasil ini tidak menjamin atlet dalam pertandingan dapat mampu menampilkan performa maksimalnya, karena situasi latihan dan situasi dalam pertandingan sebenarnya dilapangan sangat berbeda. Hal ini bisa dipengaruhi oleh beberapa faktor seperti adanya lawan bertanding, hadangan, blocking lawan dan kondisi atlet itu sendiri. Abdulloh, I. N., Saichudin, S., \& Merawati, (2018) dalam penelitiannya mengungkapkan bahwa keberhasilan dalam melakukan free throw dipengaruhi oleh analisis gerak atlet tersebut sesuai dengan prinsip dasar biomekanika. Prinsip dasar yang dimaksud dapat berupa efektifitas dan efisiensi gerakan yang dilakukan. Dalam melakukan free throw hal utama yang menjadi faktor keberhasilan tembakan adalah faktor fisik, meskipun faktor psikologi (Nanda \& Dimyati, 2019) dan non teknis seperti kelelahan (Uygur et al., 2010) juga dapat memberikan dampak terhadap free throw yang dilakukan. Akan tetapi dalam penelitian ini faktor kondisi fisik menjadi prioritas dalam pembahasan.

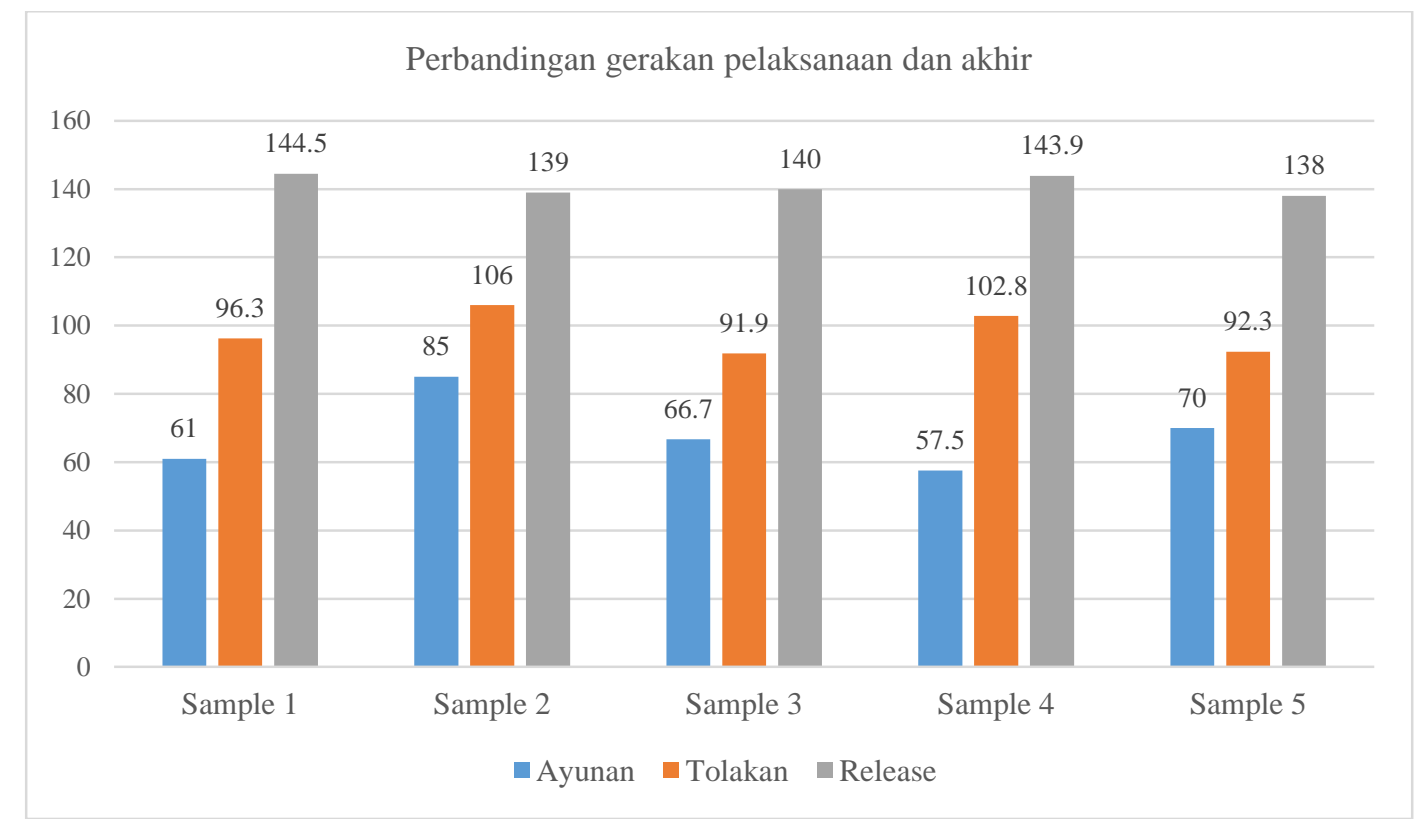

Gambar 2. Perbandingan gerakan pelaksanaan dan akhir.

Penelitian ini juga memiliki data pendukung terkait fase yang berpengaruh dalam melakukan free throw dengan hasil tembakan yang dilakukan terutama yang dipengaruhi oleh gerak dan dilakukan oleh atlet yaitu pada fase pelaksanaan dan fase akhir. Gambar 2 diatas menunjukan bahwa sampel pertama pada gerakan pelaksanaan dan akhir yang meliputi gerak ayunan, tolakan dan release menunjukan perbandingan sudut yang berbeda, ayunan lengan membentuk sudut $61^{\circ}$ dengan tolakan saat akan melakukan release sebesar $96,3^{\circ}$ dan sudut release $144,5^{\circ}$. Selanjutnya sampel kedua melakukan ayunan yang membentuk sudut $86^{\circ}$ dengan tolakan saat akan release sebesar $106^{\circ}$ dan 
sudut release sebesar $139^{\circ}$. Berikutnya yaitu sampel ketiga, ayunan membentuk sudut $66,7^{\circ}$ pada ekstensi siku dengan tolakan saat akan melakukan release sebesar $91,9^{\circ}$ dan sudut release yang dilakukan sebesar $140^{\circ}$. Sampel keempat melakukan ayunan yang dilakukan membentuk sudut sebesar $57,5^{\circ}$ dengan tolakan saat akan release sebesar $102,8^{\circ}$ dengan sudut release $143,9^{\circ}$. Sampel yang terakhir yaitu sampel ke lima membuat sudut ayunansebesar $70^{\circ}$ dengan tolakan saat akan release $92,3^{\circ}$ dan sudut release sebesar $138^{\circ}$.

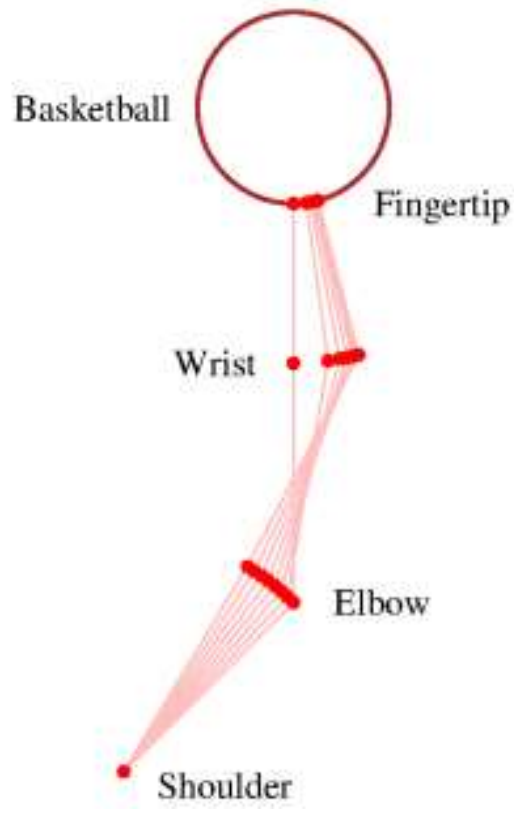

Gambar 3. Posisi lengan, siku, pergelangan tangan, dan jari (Okubo \& Hubbard, 2015)

Posisi lengan saat melakukan free throw dapat digambarkan melalui simulasi segmen lengan yang merujuk pada Okubo \& Hubbard, (2015) dimana posisi antar segmen pada siku, pergelangan tangan, dan jari memilik pengaruh terhadap hasil tembakan yang dilakukan. Gambar 3 menunjukkan posisi dan keberlanjutan gerakan melalui gambar lengan, siku, pergelangan tangan, dan jari saat melakukan tembakan. Hasil penelitian ini juga selaras dengan rujukan data dari penelitian Okubo \& Hubbard, (2015) dimana ayunan lengan membentuk sudut $45^{\circ}$ kemudian sudut siku mendekati $180^{\circ}$, dan ekstensi pergelangan tangan pada $59^{\circ}$. Secara angka data tersebut memang secara signifikan berbeda, akan tetapi dalam analisisnya data tersebut mendekati angka yang dijadikan sebagai rujukan dan pembanding dalam penelitian yang dilakukan. Sehingga data data tersebut dapat dijadikan sebagai dasar dan rujukan dalam menganalisis serta membandingkan data dalam penelitian yang dilakukan.

Menurut Alexander, Way, \& Bell, (2009) tahap akhir dari free throw adalah follow through, gerakan ini merupakan gerakan dimana semua sendi terus bergerak sampai akhir gerakan saat mengikuti rilis bola. Dalam melakukan gerakan follow through, kaki sepenuhnya diperpanjang tolakannya dan pergelangan kaki plantar flexed (jari-jari kaki menunjuk ke lantai). Posisi tubuh tegap vertikal serta pergelangan kaki membentuk sudut $90^{\circ}$ seperti posisi semula. Penjelasan tersebut sesuai dengan yang dikemukakan oleh Yulianto, (2018) dimana gerakan lanjutan yang dilakukan oleh atlet setelah melakukan gerakan free throw terus aktif meskipun tungkai hanya diam. Kesesuaian gerak (Pambudi \& Suharjana, 2018) dalam melakukan secara tidak langsung akan meminimalisasi kesalahan gerak yang nantinya dapat menyebabkan kesalahan atau bahkan pelanggaran. Hal ini akan sangat membantu dalam menurunkan tensi gerakan setelah fase pelaksanaan. Menurut Alexander et al., (2009) pemain yang tidak memiliki fleksi bahu yang cukup, siku ekstensi atau ekstensi lengan selama rilis sering melepaskan bola terlalu datar, fleksi yang tinggi diperlukan untuk memastikan bola memiliki pergerakan maksimum menuju ring.

Terkait dengan gerakan ayunan pada lengan yang dilakukan dimulai dari fase persiapan, fase awalan, fase pelaksanaan, dan fase akhir yang mempengaruhi hasil free throw maka gerakan dari setiap atlet harus benar-benar di analisis untuk mengetahui gerakan tersebut efektif atau ada faktor lain yang memiliki pengaruh terhadap hasil free throw yang dilakukan. Hermawan \& Rachman, (2018) 
menyampaikan bahwa koordinasi mata tangan terhadap ketepatan shooting memiliki pengaruh yang signifikan untuk dapat mengetahui tingkat keberhasilan bola yang masuk ke dalam ring. Lintasan bola pada free throw juga merupakan indikator dari pengaruh gerakan yang dilakukan oleh atlet. Dalam penelitian ini lintasan bola yang dibahas terkait posisi bola pada setiap fase free throw yang dilakukan.

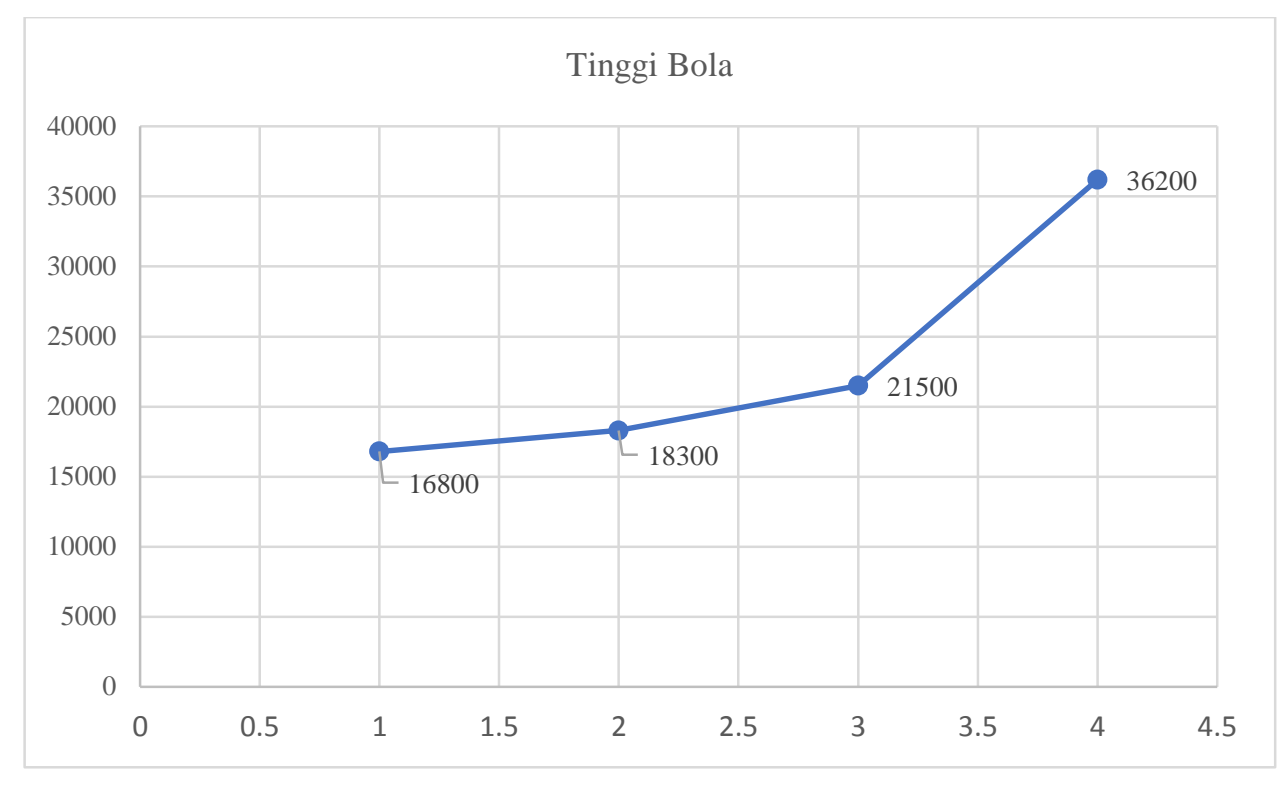

Gambar 4. Lintasan bola gerakan free throw

Lintasan bola pada gambar 4 ini merupakan posisi bola pada setiap fase gerakan free throw yang dilakukan. Fase persiapan pada free throw menunjukkan bahwa rata rata bola pada ketinggian $16800 \mathrm{~mm}$, kemudian pada fase awalan bola tersebut pada ketinggian $18300 \mathrm{~mm}$, dan pada fase pelaksanaan bola tersebut berada pada ketinggian $21500 \mathrm{~mm}$. Rata rata ketinggian bola tersebut dipengaruhi oleh rata rata tinggi badan sample yang menunjukkan angka 168,2 cm. Sebagai atlet basket, rata rata tinggi badan seorang atlet dalam penelitian ini memang kurang ideal karena setidaknya seorang atlet basket harus memiliki tinggi badan $182 \mathrm{~cm}$ untuk mampu melakukan shooting baik dalam jarak dekat maupun dalam jarak jauh (Syaukani \& Yan, 2019) saat menyerang maupun blocking saat bertahan. Pada fase akhir lintasan bola menunjukkan ketinggian $36200 \mathrm{~mm}$, posisi ini merupakan posisi bebas karena bola sudah lepas dari pegangan jari saat release. Ketinggian lintasan bola saat fase akhir ini dirasa masih kurang efektif untuk mampu mendekati ring ataupun untuk sebuah lintasan curva saat bola dilepaskan oleh pemain. Pertimbangan ini memungkinkan atlet untuk dapat melakukan shooting sesuai dengan kaidah Dave Hopla dimana pengaruh lengan dan tungkai memberikan kontribusi saat melepaskan bola kea rah ring. Perlu diketahui bahwa tinggi ring sendiri $30500 \mathrm{~mm}$. Sehingga perlu diperhatikan kesesuaian antara tinggi bola pada setiap titik lintasan bola terhadap target ring basket saat melakukan shooting. Dengan analisis gerak yang tepat akan membantu kekurangan dan keterbatasan yang ada pada setiap faktor yang dimiliki terutama postur tubuh dan komponen kondisi fisik. Koordinasi tubuh yang baik akan lebih memudahkan untuk mengontrol bola saat melakukan shooting, sehingga posisi dimanapun saat shooting tidak akan berpengaruh secara signifikan terhadap hasil shooting kearah ring basket yang dituju. Hal ini yang menjadi dasar dimana analisis gerak menjadi rujukan dalam mengetahui kebenaran, kesesuaian, efektifitas, hingga bagaimana cara memiliki penampilan yang baik terutama dalam melakukan shooting. Secara umum analisis gerak melalui tinjauan biomekanika membantu seseorang dalam peningkatan performa dan pencegahan terjadinya cidera sesuai dengan rujukan dari Irawan et al., (2016); Irawan \& Long-ren, (2019) serta untuk menguatkan keterampilan dasar (Iqroni, 2017) dalam bermain basket khususnya saat shooting. Przednowek, Krzeszowski, Przednowek, \& Lenik, (2018) dalam penelitiannya meyebutkan bahwa dalam melakukan free throw dapat dideskripsikan menggunakan sebuah sistem yang terintegrasi secara otomatis untuk dapat memantau lintasan bola. Teknik ini merupakan teknik modern dan belum banyak yang mempelajari terkait lintasan bola pada free throw basket (Kartiko et al., 2019; Kusuma, 2020). Keterbatasan dalam penelitian ini yaitu jumlah 
partisipan yang terbatas dikarenakan karena memang ada pembatasan social sesuai dengan protocol kesehatan dalam pencegahan penularan Covid-19. Peneliti juga mengalami kesulitan dalam pengumpulan data kinematic karena beberapa data di kinematic pada free throw masih kurang dalam penyajiannya melalui penelitian terdahulu.

\section{SIMPULAN}

Berdasarkan hasil penelitian dan pembahasan di atas maka dapat disimpulkan bahwa gerakan free throw Sesuai dengan kaidah dari Dave Hopla. Hasil free throw juga menunjukkan bahwa shooting precision pada kategori Cukup. Keterbatasan dalam penelitian ini adalah jumlah sample yang sedikit karena terkendala dengan protocol kesehatan dan pembatasan social pada masa pandemic Covid-19. Penelitian selanjutnya diharapkan bahwa kaidah Dave Hopla dapat dijadikan sebagai rujukan dalam melakukan free throw dan dapat mengoptimalkan efektivitas dan efisiensi gerakan serta akurasi pada hasil free throw.

\section{DAFTAR PUSTAKA}

Abdullah, M. (2015). Metode Penelitian Kuantitatif (E. Maharani (ed.); 1st ed.). Aswaja Pressindo.

Abdulloh, I. N., Saichudin, S., \& Merawati, D. (2018). Analisis Gerak Free Throw Terhadap Keberhasilan Menembak di Tim Bolabasket FIK Universitas Negeri Malang. Jurnal Sport Science, 6(2), 1-8. https://doi.org/http://dx.doi.org/10.17977/um057v6i2p116-123

Aksović, N., Bjelica, B., Milanović, F., Nikolić, D., \& Pržulj, R. (2015). Kinematic Analysis of Basketball Jump Shot. Ita. J. Sports Reh. Po, 9, 20-22.

Alexander, M., Way, D., \& Bell, M. (2009). Mechanics of the Basketball Free Throw. 1-20.

Ammar, A., Chtourou, H., Abdelkarim, O., Parish, A., \& Hoekelmann, A. (2016). Free throw shot in basketball: kinematic analysis of scored and missed shots during the learning process. Sport Sciences for Health, 12(1), 27-33. https://doi.org/10.1007/s11332-015-0250-0

Asmawan, A. Y., \& Wismanadi, H. (2019). Analisis Keberhasilan Free Throw Pada Atlet Bolabasket Putra IKOR UNESA Ditinjau Dari Segi Biomekanika. JOSSAE : Journal of Sport Science and Education, 4(1), 36. https://doi.org/10.26740/jossae.v4n1.p36-43

Boddington, B. J. (2019). The Validity and Reliability of the Basketball Jump Shooting Accuracy Test. The University of Notre Dame Autralia.

Erčulj, F., \& Štrumbelj, E. (2015). Basketball Shot Types and Shot Success in Different Levels of Competitive Basketball. PLoS ONE, 10(6), 1-14. https://doi.org/10.1371/journal.pone.0128885

Hermawan, D. A., \& Rachman, H. A. (2018). Pengaruh pendekatan latihan dan koordinasi mata tangan terhadap ketepatan shooting peserta ekstrakurikuler basket. Jurnal Keolahragaan, 6(2), 100-109. https://doi.org/https://doi.org/10.21831/jk.v0i0.20349

Hopla, D. (2013). Better Basketball Shooting. United State: human kinetics.

Hung, G. K., Johnson, B., \& Coppa, A. (2004). Aerodynamics and Biomechanics of the Free Throw. In Biomedical Engineering Principles in Sports (Issue January 2004, pp. 367-390). Kluwer Academic/Plenum Publishers. https://doi.org/10.1007/978-1-4419-8887-4_14

Iqroni, D. (2017). Model Tes Keterampilan Dasar dan Kondisi Fisik untuk Mengidentifikasi Bakat Calon Atlet Bolabasket. Jurnal Keolahragaan, 5(2), 142-150. https://doi.org/http://dx.doi.org/10.21831/jk.v5i2.15595

Irawan, F. A., Chuang, L.-R., Peng, H.-T., \& Huang, S.-K. (2016). A Biomechanical Baseball Pitching: Is the curveball has more risk than fastball? 華人運動生物力學期刊, 13(2), 55-63. https://doi.org/10.3966/207332672016121302002

Irawan, F. A., \& Long-ren, C. (2019). Baseball and biomechanics : Injury prevention for baseball pitcher. Jurnal Keolahragaan, 7(1), 57-64. https://doi.org/https://doi.org/10.21831/jk.v7i1.24636 


\section{Jurnal Keolahragaan 9 (2), 2021 - 219}

Fajar Awang Irawan, Wisnu Kerta Raharja, Tafriyadhur Risa Billah, Mirza Arif Ma'dum

Irawan, F. A., \& Long-Ren, C. (2015a). Comprehensive Pitching Biomechanics and Injury Prevention for Young Baseball Pitchers-A review. Journal of Physical Education and Sport Science, 21, $11-$ 21.

Irawan, F. A., \& Long-Ren, C. (2015b). Pitching Biomechanics and Injury Prevention to Improving Performance for Young Baseball Pitchers - A review. 1st UNNES International Conference on Research Innovation \& Commercialization for Better Life, 1-4. conf.unnes.ac.id/index.php/uicric

Irawan, F. A., Permana, D. F. W., Akromawati, H. R., \& Yang-tian, H. (2019). Biomechanical Analysis of Concentration and Coordination on The Accuracy in Petanque Shooting. Journal of Physical Education, Sport, Health and Recreations, 8(2), 96-100. https://doi.org/https://doi.org/10.15294/active.v8i2.30467

Kartiko, D. C., Tuasikal, A. R. S., Al Ardha, M. A., \& Yang, C. B. (2019). Biomechanical Analysis of Ball Trajectory Direction in Free Throw. Aadvances in Social Science, Education, and Humanities Research, 335(ICESSHum), 449-453. https://doi.org/10.2991/icesshum-19.2019.73

Kusuma, I. D. M. A. W. (2020). Kinematika gerak yang mempengaruhi kecepatan bola pada teknik passing permainan futsal. Jurnal SPORTIF: Jurnal Penelitian Pembelajaran, 6(3), 674-683. https://doi.org/https://doi.org/10.29407/js_unpgri.v6i3.14785

Nanda, F. A., \& Dimyati, D. (2019). The psychological skills of basketball athletes : Are there any differences based on the playing position? Jurnal Keolahragaan, 7(1), 74-82. https://doi.org/https://doi.org/10.21831/jk.v7i1.26360

Okubo, H., \& Hubbard, M. (2015). Kinematics of Arm Joint Motions in Basketball Shooting. Procedia Engineering, 112, 443-448. https://doi.org/10.1016/j.proeng.2015.07.222

Pambudi, D. K., \& Suharjana, S. (2018). Pengembangan video pembelajaran sinyal-sinyal wasit bola basket untuk guru penjasorkes sekolah menengah atas. Jurnal Keolahragaan, 6(1), 48-59. https://doi.org/http://dx.doi.org/10.21831/jk.v6i1.11880

Przednowek, K., Krzeszowski, T., Przednowek, K. H., \& Lenik, P. (2018). A System for Analysing the Basketball Free Throw Trajectory Based on Particle Swarm Optimization. Applied Sciences (Switzerland), 8(11), 1-14. https://doi.org/10.3390/app8112090

Rubiana, I. (2017). Pengaruh Pembelajaran Shooting free throw dengan alat bantu rentangan tali terhadap hasil shooting dalam permainan bola basket. Jurnal Siliwangi, 3(2), 248-257. https://doi.org/10.37058/jspendidikan.v3i2.337

Rudiansyah, E., Usman, A., \& Hakim, A. F. (2014). Upaya Meningkatkan Shooting Free Throw Permainan Bola Basket Dengan Metode Strength Pada Siswa Kelas X Akuntansi 2 SMK Negeri 1 Nanga Pinoh. Jurnal Pendidikan Jasmani Kesehatan Dan Rekreasi, 1(1), 64-68. https://doi.org/https://doi.org/10.46368/jpjkr.v1i1.55

Sartika. (2010). PERATURAN RESMI BOLA BASKET. 434, 1-10.

Syaukani, A. A., \& Yan, L. C. (2019). Kinematic differences on mid-range basketball jump-shot between experienced and less-experienced collegiate player. Jurnal Keolahraan, 7(1), 1-10. https://doi.org/https://doi.org/10.21831/jk.v7i1.21541

Uygur, M., Goktepe, A., Ak, E., Karabörk, H., \& Korkusuz, F. (2010). The Effect of Fatigue on the Kinematics of Free Throw Shooting in Basketball. Journal of Human Kinetics, 24(1), 51-56. https://doi.org/10.2478/v10078-010-0019-0

Yulianto, P. F. (2018). Biomekanika Gerakan Lemparan Bebas ( Free Throw) Dalam Permainan Bola Basket. Proceeding Seminar Nasional Biomekanika Olahraga, 38, 1-12. 